\title{
Research Paper: Evaluation of Death Anxiety in Elderly Patients With Cancer Undergoing Chemotherapy
}

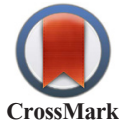

Farideh Bastani $^{1}$, Fattaneh Farnood ${ }^{1 *}$, Hamid Haqhani ${ }^{2}$

1. Department of Geriatric Nursing, School of Nursing \& Midwifery, Iran University of Medical Sciences, Tehran, Iran.

2. Department of Biostatistics, School of Health, Iran University of Medical Sciences, Tehran, Iran.

Crtation: Bastani, F., Farnood, F., Haqhani, H. 2016. Evaluation of Death Anxiety in Elderly Patients With Cancer Undergoing Chemotherapy. Journal of Client-Centered Nursing Care, 2(3), pp. 153-160. https://doi.org/10.32598/jccnc.2.3.153

dol: $:$ https://doi.org/10.32598/jcenc.2.3.153

Article info:

Received: 24 Nov. 2015

Accepted: 19 Mar. 2016

Keywords:

Aging, Cancer, Death anxiety

\begin{abstract}
A B S T RA C T
Background: Aging population and prevalence of diseases like cancer among them have affected general health of the elderly, so that one of the influential factors on health components of elderly patients with cancer is death anxiety, which has important consequences in them.

Methods: In this cross-sectional (descriptive correlational) study, 130 elderly patients with cancer undergoing chemotherapy were recruited by convenience sampling method. To collect information, demographic information form and Templer's death anxiety inventory were used. To analyze the data, descriptive statistics, statistical tests were used through SPSS 21.

Results: The results showed that $42.3 \%$ of the old people had high death anxiety. The mean (SD) score of death anxiety was found 6.85 (2.7) which was at the desirable level. In this study, death anxiety of old people had significant relationship with variables of age $(\mathrm{P}<0.001)$, marital status ( $\mathrm{P}<0.012)$, education level $(\mathrm{P}<0.001)$, cancer type $(\mathrm{P}<0.023)$, period of suffering from cancer $(\mathrm{P}<0.018)$, and other comorbid diseases $(\mathrm{P}<0.001)$. So that old people with lower age, higher level of education, married, lower period of cancer, and without underlying diseases, had lower death anxiety.
\end{abstract}

Conclusion: The results of this study can be a basis for better understanding of educational consultation, and supporting needs regarding coping with anxiety and its management (based on the culture of the community) in this group of elderly patients with cancer.

\section{Background}

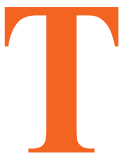

he ever-increasing population of elderly people in the world is to the extent that has been described as silent revolution (Azadchehr et al. 2014). According to the report by the World Health Organization in 2014 , in the next 40 years, the world's population over 65 years will be doubled and out of them, $52 \%$ live in
Asian countries and $40 \%$ in developing countries (WHO 2014). According to the latest census in 2011, the over 60 years population in Iran was $6159676(8.2 \%)$ people and had an increasing trend in comparison with 2006 census results (Statistics Center of Iran 2012). Because the average age of the population is increasing, it is anticipated that non-communicable diseases, including cancer rises as well (Naghavi 2006). Cancer is one of the major causes of mortality in human societies, and accounts for

\footnotetext{
* Corresponding Author:
}

Fattaneh Farnood, MSc.

Address: Department of Geriatric Nursing, School of Nursing \& Midwifery, Iran University of Medical Sciences, Tehran, Iran

Tel: +98 (937) 0119163

E-mail:fataneh_farnood@yahoo.com 
$10 \%$ of all deaths in the world by 2015 . With regard to changes in the population age pyramid, increasing the elderly population, and their prolonged exposure to carcinogens, incidence of cancer in this population has been increased (Schoenberg \& Halle 2009). In the last two decades, the number of old people with cancer has increased (Engels et al. 2011) in a way that cancer now is one of the leading cause of death in the older people (Jorgense et al. 2012).

Diagnosis of cancer, more than any other disease, is an unpleasant and unbelievable experience, which interrupts the occupation, socioeconomic status, and family life of the patient. One of the factors affecting the mental health of cancer patients is death and its anxiety. Anxiety is a psychological and physiological state which has cognitive, physical, emotional, and behavioral components (Burke, Martens \& Faucher 2010). Death anxiety, which is the most basic form of anxiety (Fritsche et al. 2010), is defined as an abnormal and great fear along with emotions such as death panic with anxiety when thinking about the process of dying or things that happen after death. Since the death has not been experienced yet and nobody has clearly touched it, all people are somehow anxious about it and everybody experience varying levels of death anxiety based on certain factors (Naderi \& Roushani 2012).

Various studies in the field of death anxiety have been conducted on patients with physical problems and its effects on the disease progression which confirms the central role of this concept in the field of nursing. One study findings indicate that by catching a physical disease, in particular, specific diseases such as cancer, AIDS, epilepsy, and so on, death anxiety becomes a major problem in patients (Mohamadi et al. 2013). In this regard, patients with malignant diseases such as cancer are considered as vulnerable population. In most cases, the treatment is more focused on fixing physical symptoms of patients, while as by disease progression and manifestation of its associated symptoms, patients are afraid of pain, suffering, loneliness, punishment, and loss of control. All of these have been identified as dimensions of death anxiety (Grady, Knebel \& Draper 2001).

Death anxiety in this group of patients can affect their quality of lives by distorting their mental and spiritual aspects. Therefore, identifying components which may have an impact on the quality of life of cancer patients is important (Janda et al. 2009). Based on the reports, cancer patients experience high degree of death anxiety so that the prevalence of death anxiety in patients with cancer was $17.9 \%$, compared to the healthy group as $9.13 \%$
(Tan et al., 2014). In another study, there was a high degree of death anxiety in cancer patients (Vilhauer 2008).

In Iran, Salehi, Mohsenzade and Arefi (2016) studied the prevalence of death anxiety in young and middleaged patients with breast cancer and most of the subjects had a high level of death anxiety (72.9\%). However, few such reports about the old people have been published, and especially older patients with cancer undergoing chemotherapy. Also, as the aging population and the number and variety of stressors people face in old age have been accelerated in recent years, paying attention to the mental health in old age has become a priority (Beery et al. 2002).

Despite the importance of death anxiety, studies on death anxiety in older patients with cancer have been scarce and decisive conclusion cannot be made because of insufficient knowledge. Therefore, considering the high prevalence of cancer, its destructive impact on mental health in patients, relationship of death anxiety concept to sociocultural and religious factors, and few Iranian studies in this topic, this study was conducted to determine death anxiety and its related factors in elderly patients with cancer undergoing chemotherapy.

\section{Materials and Methods}

The cross-sectional study is a descriptive and correlational. The study samples comprised old people (60 to 75 years) with different kinds of cancer undergoing chemotherapy in the Oncology Ward of Kosar Medical Education Hospital of Semnan (2015). To determine the sample size, the confidence level was set at $95 \%$ and power at $80 \%$. Also, it was assumed that the correlation coefficient between the death anxiety and mental health in older patients with cancer undergoing chemotherapy was at least 0.25 to have a significant relationship between the two variables. Therefore, the sample size was estimated as 130 .

Study samples were enrolled by convenient sampling method. The inclusion criteria were as follows: 1) lack of cognitive impairment or depression (with a score of 7 obtained from abbreviated mental test score), 2) experienced at least one round of chemotherapy, 3) be aware of their disease, 4) ability to respond to the questionnaire, and 5) ability to communicate and lack of any specific mental illness (based on medical records). To comply with research ethics issues, after approval by the Ethics Committee (Code of ethics IR.IUMS. REC.1394.9311850008), the researcher referred to the research setting and explained the purpose of research and how to perform it to the person in charge. After 
obtaining the approval of the relevant authorities, the researcher began the study. The samples initially filled written consent forms and then the questionnaires were given to them to complete.

The first questionnaire was related to patients' demographic information, which included variables such as age, gender, marital status, occupation, education, housing, economic status, type of cancer, course of chemotherapy, duration of disease, other diseases, and particular recent crisis in the life (e.g. marriage, death of relatives, and retirement). The second questionnaire was Templer's death anxiety scale, which was built in 1970 by Templer and contains 15 questions measuring the attitudes of people toward death.

People specify their response to each question with yes or no. "Yes" indicates the presence of anxiety in person. Thus, the scale score ranges between 0 and 15 . High scores ( 8 and upper) represent high anxiety about death (Templer 1970). Templer's death anxiety scale is a standard questionnaire which has been widely used in various studies worldwide to measure death anxiety. It has also translated, factor analyzed, and validated in Iran. Rajabi and Bahrani investigated this scale on 130 students in the city of Ahvaz and reported its reliability coefficient and internal consistency coefficient as $60 \%$ and $73 \%$, respectively (Rajabi \& Bohrani 2001). In the present study, the reliability and validity have been investigated and the reliability ( $\mathrm{r}$ ) of the questionnaire was 0.80 .

Data analysis was conducted by descriptive statistics (distribution percentage, frequency, mean and standard deviation) and inferential statistics (ANOVA, t-test, Kruskal-Wallis, Pearson correlation, and linear regression), at significance level of $\mathrm{P}<0.05$, using SPSS 21 .

\section{Results}

The results showed that the participants' mean (SD) age was $66.88 \pm 4.86$ years (age range: $60-75$ years). Of 130 samples, $65(50 \%)$ patients were female and 59.2\% of them were married. Intestine was the most common site for cancer (30.8\%). Other demographic information of subjects is presented in Table 1. The mean and standard deviation of death anxiety score in old people undergoing chemotherapy was $6.85 \pm 2.79$. Seventy-five (57.7\%) study patients had low death anxiety and 45 patients $(42.3 \%)$ had high death anxiety. According to the findings and statistical analysis, there was a significant relationship between death anxiety and variables of age $(\mathrm{P}<0.001)$, marital status $(\mathrm{P}<0.012)$, education $(\mathrm{P}<$ $0.001)$, type of cancer $(\mathrm{P}<0.023)$, duration of cancer $(\mathrm{P}$
$<0.018)$ and having other diseases $(\mathrm{P}<0.001)$. There was not a significant relationship between death anxiety and variables of gender $(\mathrm{P}=0.273)$, occupation $(\mathrm{P}=$ $0.173)$, financial status ( $\mathrm{P}=0.139)$, housing $(\mathrm{P}=0.526)$, courses of chemotherapy $(\mathrm{P}=0.116)$, and the recent crisis in life $(\mathrm{P}=0.775)$ (Table 1$)$.

According to Table 1, the ANOVA results showed that the mean score of death anxiety in older patients with cancer had a significant relationship with age $(\mathrm{P}<0.001)$. Scheffe test shows that this difference exists between age group over 70 years with the other two age groups $(\mathrm{P}<0.001)$ and the average anxiety score is higher in this age group, too.

With regard to marital status, the mean score of death anxiety had a significant difference in at least one of the groups with the other groups $(\mathrm{P}=0.012)$. The Scheffe test indicates that the difference exists between married group with the widowed and divorced groups. Based on the results, the average anxiety score was lower in married group $(\mathrm{P}=0.016)$. The ANOVA results showed a statistically significant relationship between the level of death anxiety and education of older patients with cancer $(\mathrm{P}<0.001)$. Scheffe test showed that this difference was significant between the old people who had higher education with those who had an elementary level of education or illiterate as well as between old people graduated with diploma and those with primary education and illiterates. Based on the results, death anxiety was higher in old people who were illiterate or passed primary school compared to other groups.

Statistical analysis also showed a significant relationship between anxiety and duration of cancer $(\mathrm{P}=0.018)$. Scheffe test indicated that the difference was between old people affected by the cancer for less than 12 months and old people with cancer for more than 24 months $(\mathrm{P}=$ 0.022 ). This means that old people who suffer from cancer for less than 12 months feel less death anxiety than those with more than 24 months. Also, based on the results, it was found that a significant relationship exists between the mean score of death anxiety and cancer type $(\mathrm{P}=0.023)$.

The highest and the lowest mean score of death anxiety belonged to ovarian and breast cancer, respectively. In addition, there is a significant relationship between the mean score of death anxiety and duration of cancer. The results of Scheffe test indicated that this difference was between old people who were affected by cancer for less than a year and old people affected for more than two years $(\mathrm{P}=0.022)$.

Table 2 presents death anxiety in old patients with cancer undergoing chemotherapy with respect to separate 
Table 1. Demographic and clinical characteristics and death anxiety scores of the participants

\begin{tabular}{|c|c|c|c|c|c|}
\hline \multirow{2}{*}{ Variable } & & \multirow{2}{*}{ No. } & \multirow{2}{*}{$\%$} & Death Anxiety & \multirow{2}{*}{$\begin{array}{l}\text { Test Signifi- } \\
\text { cance }\end{array}$} \\
\hline & & & & Mean \pm SD & \\
\hline \multirow{3}{*}{ Age (year) } & $60-64$ & 47 & 36.20 & $5.34 \pm 2.63$ & \multirow{3}{*}{$P<0.001$} \\
\hline & $65-69$ & 42 & 32.30 & $6.59 \pm 2 . .48$ & \\
\hline & $70-75$ & 41 & 31.50 & $8.85 \pm 1.98$ & \\
\hline \multirow{3}{*}{ Marital status } & Single & 77 & 59.20 & $6.00 \pm 2.82$ & \multirow{3}{*}{$P<0.012$} \\
\hline & Married & 5 & 3.80 & $6.32 \pm 2.88$ & \\
\hline & Widowed or divorced & 48 & 36.90 & $7.79 \pm 2.42$ & \\
\hline \multirow{3}{*}{ Occupation } & Employed & 22 & 16.90 & $5.86 \pm 3.37$ & \multirow{3}{*}{$P=0.173$} \\
\hline & Housewife & 49 & 37.70 & $7.18 \pm 3.05$ & \\
\hline & Retired & 59 & 45.40 & $6.94 \pm 2.66$ & \\
\hline \multirow{5}{*}{ Education } & Illiterate & 19 & 14.60 & $8.47 \pm 2.11$ & \multirow{5}{*}{$P<0.001$} \\
\hline & Elementary & 35 & 26.90 & $7.91 \pm 2.57$ & \\
\hline & Secondary & 23 & 17.70 & $6.82 \pm 2.99$ & \\
\hline & Diploma & 35 & 26.90 & $6.00 \pm 2.79$ & \\
\hline & Academic & 18 & 13.8 & $4.77 \pm 1.62$ & \\
\hline \multirow{3}{*}{ Financial status } & Poor & 19 & 14.6 & $8.00 \pm 2.05$ & \multirow{3}{*}{$P=0.139$} \\
\hline & Average & 88 & 67.7 & $6.82 \pm 2.84$ & \\
\hline & Good & 23 & 17.7 & $6.04 \pm 2.95$ & \\
\hline \multirow{3}{*}{ Housing status } & Owned & 70 & 53.8 & $6.70 \pm 2.76$ & \multirow{3}{*}{$P=0.526$} \\
\hline & Rental & 40 & 30.8 & $7.50 \pm 3.00$ & \\
\hline & Mortgaged & 20 & 15.4 & $6.80 \pm 2.75$ & \\
\hline \multirow{8}{*}{ Cancer type } & Breast & 24 & 18.5 & $5.25 \pm 2.67$ & \multirow{8}{*}{$P=0.023$} \\
\hline & Stomach & 15 & 11.5 & $5.80 \pm 3.02$ & \\
\hline & Bladder & 12 & 9.2 & $7.33 \pm 3.36$ & \\
\hline & Blood & 13 & 10.0 & $7.84 \pm 2.51$ & \\
\hline & Intestine & 40 & 30.8 & $7.30 \pm 2.61$ & \\
\hline & Lung & 7 & 5.4 & $6.57 \pm 1.90$ & \\
\hline & Prostate & 10 & 7.7 & $7.50 \pm 2.17$ & \\
\hline & Ovary & 9 & 6.9 & $8.33 \pm 2.64$ & \\
\hline \multirow{3}{*}{ Duration of cancer (month) } & $<12$ & 53 & 40.8 & $6.20 \pm 3.01$ & \multirow{3}{*}{$P=0.018$} \\
\hline & $13-24$ & 48 & 37 & $6.63 \pm 2.74$ & \\
\hline & $>24$ & 29 & 22.2 & $7.87 \pm 2.31$ & \\
\hline \multirow{4}{*}{ Duration of chemotherapy } & $1-3$ & 44 & 48.5 & $6.34 \pm 2.98$ & \multirow{4}{*}{$P=0.116$} \\
\hline & $4-6$ & 24 & 20.0 & $6.50 \pm 2.68$ & \\
\hline & $7-12$ & 30 & 14.6 & $6.83 \pm 2.57$ & \\
\hline & $>13$ & 32 & 16.9 & $7.84 \pm 2.65$ & \\
\hline \multirow{2}{*}{ Other disease than cancer } & Yes & 60 & 46.2 & $8.03 \pm 2.62$ & \multirow{2}{*}{$P<0.001$} \\
\hline & No & 70 & 53.8 & $5.84 \pm 2.53$ & \\
\hline \multirow{2}{*}{ Recent crisis } & Yes & 34 & 26.2 & $6.73 \pm 2.50$ & \multirow{2}{*}{$P=0.775$} \\
\hline & No & 96 & 73.8 & $6.89 \pm 2.90$ & \\
\hline
\end{tabular}


Table 2. Frequency distribution of answers to questions of death anxiety items in old patients with cancer undergoing chemotherapy

\begin{tabular}{|c|c|c|c|c|c|}
\hline \multirow{2}{*}{ Question About Death Anxiety } & \multicolumn{2}{|c|}{ Yes } & \multicolumn{2}{|c|}{ No } & \multirow{2}{*}{ Mean \pm SD } \\
\hline & $\%$ & No. & $\%$ & No. & \\
\hline 1. Do you worry about dying? & 61.5 & 80 & 38.5 & 50 & $0.488 \pm 0.62$ \\
\hline 2. Are you worried to die before doing your works? & 63.1 & 82 & 36.9 & 48 & $0.484 \pm 0.63$ \\
\hline 3. Are you worried to suffer from disease for a long time before dying? & 73.1 & 95 & 26.9 & 35 & $0.445 \pm 0.730$ \\
\hline 4. Does it annoy you that others may pay attention to your suffering when you are dying? & 37.7 & 49 & 62.3 & 81 & $0.486 \pm 0.38$ \\
\hline 5. Are you worried that the death may be very painful? & 42.3 & 55 & 57.7 & 75 & $0.496 \pm 0.42$ \\
\hline 6. Do you think that when you are dying, closest people to you worry about you? & 43.8 & 57 & 56.2 & 73 & $0.498 \pm 0.44$ \\
\hline 7. Are you worried about being alone at the time of death? & 56.9 & 74 & 43.1 & 56 & $0.497 \pm 0.57$ \\
\hline 8. Do you think that before death you lose control of your mind? & 33.1 & 43 & 66.9 & 87 & $0.472 \pm 0.33$ \\
\hline 9. Are you worried that your funeral expenses be expensive for others? & 30.0 & 39 & 70.0 & 91 & $0.460 \pm 0.30$ \\
\hline 10. Are you worried that after your death your belongings and wills left unaccomplished? & 36.9 & 48 & 63.1 & 82 & $0.484 \pm 0.37$ \\
\hline 11. Are you afraid that you might be buried before you really die? & 8.5 & 11 & 91.5 & 119 & $0.279 \pm 0.08$ \\
\hline 12. Does it make you upset to leave your loved ones when dying? & 85.4 & 111 & 14.6 & 19 & $0.355 \pm 0.85$ \\
\hline $\begin{array}{l}\text { 13. Are you worried that those who are worried about you, do not remember you } \\
\text { after your death? }\end{array}$ & 38.5 & 50 & 61.5 & 80 & $0.488 \pm 0.38$ \\
\hline 14. Do you think that you are worried that you will be destroyed forever with death? & 29.2 & 38 & 70.8 & 92 & $0.457 \pm 0.29$ \\
\hline 15. Are you worried because you do you not know what will happen after death? & 45.4 & 59 & 54.6 & 71 & $0.500 \pm 0.45$ \\
\hline
\end{tabular}

Table 3. Linear regression analysis on the effects of demographic variables on death anxiety

\begin{tabular}{|c|c|c|c|c|c|}
\hline & Independent Variables & Coefficient & Statistics & P-Value & $\mathbf{R}^{2}$ \\
\hline \multirow{2}{*}{ Marital status } & Single & -0.410 & 0.349 & 0.727 & \\
\hline & Married & -0.668 & 1.386 & 0.167 & \\
\hline \multirow{4}{*}{ Level of education } & Elementary & 0.484 & 0.693 & 0.489 & \\
\hline & Secondary & -0.631 & 0.835 & 0.406 & \\
\hline & Diploma & -0.784 & 1.014 & 0.313 & 0.345 \\
\hline & Academic & 1.437 & 1.544 & 0.125 & \\
\hline Age (year) & & 0.174 & 3.009 & 0.003 & \\
\hline Duration of cancer & & 0.023 & 0.962 & 0.338 & \\
\hline Other diseases & & 0.698 & 1.356 & 0.178 & \\
\hline
\end{tabular}


items. Most "Yes" answers belonged to the question No. 12 of the questionnaire "Does it make you upset to leave your loved ones when dying?" and most "No" answers was related to the question No. 11 of the questionnaire: "Are you afraid of being buried before you really die?"

According to Table 3, age was the only significant variable in the regression model. It can be seen that its coefficient was 0.174 , meaning that with an increase of one year, death anxiety increases by 0.174 and obtained coefficients for other variables in the regression model was not significant.

\section{Discussion}

Our study was conducted on the effects of death anxiety and its related factors in old patients with cancer undergoing chemotherapy. Based on the results, 57.7\% of old patients with cancer had low death anxiety and $42 \%$ of old patients, a fairly significant number, had high death anxiety. This indicates that one of the factors affecting the mental health in cancer patients is death anxiety (Lehto \& Stein 2009). In a study by Sherman et al. cancer patients had moderate to high death anxiety (Sherman et al., 2010). The results of Bahrami et al. study on women with breast cancer shows the moderate to high death anxiety among them (Bahrami et al. 2013). In Henry et al. study, carried out on a different population, death anxiety in samples was low.

This different result (compared to the current study) could be due to the fact that most cancer patients are engaged with death anxiety and cognitive distortions and negative thoughts of their symptoms (Yousofi 2013). Fear of death is natural and in fact, it would seem abnormal if one were not afraid of death. Therefore, it can be said that the fear of death occur only in the old people. However, this kind of fear may increase with age and might reach to maximum amount possible in old age, in a way that in Ghorbanali pour and Ismaili study, death anxiety was high in old patients (Ghorbanalipour \& Esmaili 2012).

There was a significant relationship between the mean score of age and death anxiety in older patients with cancer in a way that death anxiety increases by 0.174 with age and this finding is consistent with the results of Bonder et al. study conducted to investigate the effect of aging on death anxiety. The findings showed that aging and aging-related anxiety is positively associated with death anxiety (Bonder et al., 2015). This could be possibly due to the effect of increasing age on variables such as employment, marital status, socioeconomic status, loneliness, and physical disabilities.
In this study, marital status has been recognized as a factor related to death anxiety in old patients with cancer. The results indicated statistically significant correlation between death anxiety in the old patients and marital status in a way that the divorced and widowed groups had higher death anxiety scores compared to the married group. The results of Shojaee et al. study on the mental health and its relationship with social capital of old people in District 9 of Tehran showed that old married people enjoyed better mental health than old single ones (Shoja et al., 2013). Muramatsu also in a study conducted on a group of old Americans found that single, widowed, or divorced old people enjoyed less mental health than their married counterparts (Muramatsu, Yin \& Hedeker 2010). Karren et al. also believed that separated people and those who are dissatisfied with their marriage suffered serious health problems of their own. Of course, this effect depends on the age and gender of individuals. Separated individuals have lost a great source of social support i.e. the family, which impose another stress besides their disease (Karren et al., 2002).

With higher educational levels, the average score of the subjects regarding death anxiety reduces. Based on the results of ANOVA, the relationship between death anxiety and level of education was significant and old people with a higher education had less death anxiety compared to those illiterate old people or those with elementary education. Consistent with the above results, a study by Salehi et al. also shows high death anxiety among cancer patients with a poor education and literacy (Salehi, Mohsenzade \& Arefi 2016). In this regard, in a study conducted in a city in Colombia, Harpham et al. found that people with higher education enjoy better mental health (Harpham, Grant \& Rodriguez 2004). Azaiza et al. also showed that there was a difference between education and death anxiety in a way that illiterate and semi-literate people experience death anxiety more than educated people (Azaiza et al. 2010).

However, in Bahrami et al. study no difference was observed between different levels of education and death anxiety (Bahrami et al. 2013). It can be stated that higher self-confidence of people, as well as increased social interaction can lead to better self-control of the disease, reduction of stress and anxiety in doing personal affairs as well as performing social roles, and ultimately their better mental health. The social and cultural constraints as well as inability in using effective methods of coping with stressors can be the reason of high anxiety in people with lower education degrees. On the other hand, if less anxiety is considered as a sign of stress management in old people (which is mentioned as a healthy and health 
promoting behavior), these findings is consistent with the results by Habibi et al. on health promoting behaviors and related factors in old people regarding the fact that healthy behaviors have a significant relationship with the level of education in old people (Habibi et al., 2006).

Also, there is a significant relationship between the mean score of death anxiety and duration of cancer. In other words, with increasing disease duration, death anxiety also increases. This could be justified because by longer duration of cancer, treatment and facing side effects of chemotherapy, along with progression of the disease and its symptoms, patients are gradually exposed to the reality of their serious illness and afraid of pain, suffering, loneliness, punished and reduced control.

The results showed that the mean score of death anxiety in old patients with cancer and other diseases had statistically significant difference; in the other words, old people who were just diagnosed with cancer and no other diseases, had lower death anxiety, which seems to be obvious. Generally, old people are more likely to develop chronic diseases with increasing age (Prakash, Choudhary \& Singh 2004). Recent studies show that $80 \%$ of old people have at least one chronic disease which expose them more than others to the risk of disability and death (Woo et al. 2007).

In the present study, the death anxiety and gender were significantly related. While in Mansour Nezhad et al. study, which examined the religious orientation and gender with death anxiety, women had higher death anxiety. It can be explained by the fact that women accept irritating feelings regarding death but men mostly avoid it, a justification that matches with the emotional expressiveness of women during life (Mansornezhad et al. 2011). However, Mansourinezhad investigated the young population (unlike our study on old people) and possibly with aging, men might become aware of the risk of death as women and develop similar anxiety.

The study limitations include self-report questionnaires. Thus the psychological conditions of the old people could affect the results with regard to age, illness, and type of the questionnaire at the time of response. Also, because of cultural reasons, participants might evade responding to some questions. Therefore, we tried to establish an intimate relationship with them to overcome this problem. The results also cannot be generalized to the private centers and other religions, given that this study has been conducted in a government center (because of the availability of sampling).
In conclusion, a significant number of old people with cancer had high death anxiety. Furthermore, widowed and divorced old people with low level of education (illiterate and elementary level) or old people who are affected with diseases other than cancer have high death anxiety. Therefore, more social and psychological support for this group of frail old people should be provided. With regard to holistic approach and paying attention to all aspects of human existence, the health team and especially nurses should be aware of the importance of the fear of death in old people.

In addition, comprehensive care program can play an important role in reduction of the psychological problems of the old people. It is also recommended that this study be conducted for patients with chronic diseases (such as heart, AIDS, asthma, etc.) or caregivers, as they have a close relationship with their health status. Also in this study, no significant relationship was found between gender and death anxiety in old patients with cancer. Therefore it is suggested that a study be conducted to investigate more this relationship.

\section{Acknowledgments}

This article is adapted from a Master's thesis, sponsored by University of Medical Sciences and health services of Iran. The authors express their gratitude towards the Research Department of the University and Deputy of Nursing and Midwifery College in Iran and also respected authorities of Kosar Hospital of Semnan and respectful staff of Oncology Ward. Our gratitude is expressed towards all who participated as subjects in this study.

\section{Conflict of Interest}

The authors declared no conflict of interests.

\section{References}

Azadchehr, M. J., Rahgozar, M., Karimloo, M., Adib Haj Bageri, M 2014. [To identify some factors effective on survival of the elderly living in nursing home using Copula Competing Risk Model: Bayesian approach (Persian)]. Journal of Health Promotion Management, 3(4), pp. 46-55

Azaiza, F., Ron, P., Shoham, M., \& Gigini, I. 2010. Death and dying anxiety among elderly Arab muslims in Israel. Death Studies, 34(4), pp. 351-364. doi: 10.1080/07481181003613941

Bahrami, N., Moradi, M., Soleimani, M. A., Kalantari, Z. \& Hosseini, F. 2013. [Death anxiety and its relationship with quality of life in 
women with cancer (Persian)]. Iran Journal of Nursing, 26(82), pp. 51-61.

Beery, T. A., Baas, L. S., Fowler, C., \& Allen, G. 2002. Spirituality in Persons with Heart Failure. Journal of Holistic Nursing, 20(1), pp. 5-25. doi: 10.1177/089801010202000102

Bodner, E., Shrira, A., Bergman, Y. S., Cohen-Fridel, S., \& Grossman, E. S. 2015. The interaction between aging and death anxieties predicts ageism. Personality and Individual Differences, 86, pp. 15-19. doi: 10.1016/j.paid.2015.05.022

Burke, B. L., Martens, A. \& Faucher, E. H. 2010. Two decades of terror management theory: A meta-analysis of mortality salience research. Personality and Social Psychology Review, 14(2), pp. 155-195. doi: $10.1177 / 1088868309352321$

Engels, E. A., Pfeiffer, R. M., Ricker, W., Wheeler, W., Parsons, R. \& Warren, J. L. 2011. Use of surveillance, epidemiology, and end results-medicare data to conduct case-control studies of cancer among the us elderly. American Journal of Epidemiology, 174(7), pp. 860-870. doi: 10.1093/aje/kwr146

Fritsche, I., Jonas, E., Kayser, D. N., \& Koranyi, N. 2010. Existential threat and compliance with pro-environmental norms. Journal of Environmental Psychology, 30(1), pp. 67-79. doi: 10.1016/j.jenvp.2009.08.007

Ghorbanalipour, M, Esma'ili, A. 2012, [Determining the efficacy of logo therapy in death anxiety among the older adults (Persian)] Culture Counseling, 3(9), pp. 53-68. doi: 10.22054/qccpc.2012.6063

Grady, P. A., Knebel, A. R., \& Draper, A. 2001. End-of-life issues in AIDS: The research perspective. Journal of the Royal Society of Medicine, $94(9)$, pp. 479-82.

Habibi, A., Nikpour, S., Seyedoshohadaei, M., \& Haghani, H. 2006. [Health promoting behaviors and its related factors in elderly (Persian)]. Iran Journal of Nursing, 19(47), pp. 35-48.

Harpham, T., Grant, E., \& Rodriguez, C. 2004. Mental health and social capital in Cali, Colombia. Social Science \& Medicine, 58(11), pp. 2267-77. doi: 10.1016/j.socscimed.2003.08.013

Janda, M., DiSipio, T., Hurst, C., Cella, D., \& Newman, B. 2009. The Queensland cancer risk study: General population norms for the Functional assessment of cancer therapy-general. Psycho-Oncology, 18(6), pp. 606-614. doi: 10.1002/pon.1428

Jørgensen, T. L., Hallas, J., Friis, S., \& Herrstedt, J. 2012. Comorbidity in elderly cancer patients in relation to overall and cancer-specific mortality. British Journal of Cancer, 106(7), pp. 1353-1360. doi: 10.1038/bjc.2012.46

Karren, K.J., Hafen, B.Q., Smith, N.L. \& Frandsen, K.J. 2002. Body/ mind health: The effects of attitudes, emotions, and relationships. Sanfrancisco: Pearson.

Lehto, R. H. \& Stein, K. F. 2009. Death anxiety: An analysis of an evolving concept. Research and Theory for Nursing Practice, 23(1), pp. 23-41. doi: 10.1891/1541-6577.23.1.23

Mansour nezhad, Z., kajbaf, M. B., kiyani, F., poursaeid, R. 2011. [Investigating the relationship between religious orientation (inside, outside) and sex with death anxiety among students (Persian)] Journal of New findings in psychology, 5(15), pp. 135-143.

Mohammadi, M., Touri Moghaddam, C., Shahsavarani, A., Sabze Ara Langroodi, M. 2013. [Comparing the relationship between self-esteem and mental health in the prediction of death anxiety (Persian)]. Journal of Psychological Science, 12(47), pp. 343-365.
Muramatsu, N., Yin, H., \& Hedeker, D. 2010. Functional declines, social support, and mental health in the elderly: Does living in a state supportive of home and community-based services make a difference. Social Science \& Medicine, 70(7), pp. 1050-8. doi: 10.1016/j. socscimed.2009.12.005

Naderi, F., Roushani, Kh. 2012. [Relationship of spiritual intelligence and social intelligence with death anxiety in old women (Persian)]. Journal of Women and Culture, 2(6). pp. 55-67.

Naghavi, M. 2006. [Health manifestation modification in Iran (Persian)]. Journal of Iranian Epidemiology, 1(3), pp. 13-25.

Prakash, R., Choudhary, S. K., \& Singh, U. S. 2004. A study of morbidity pattern among geriatric population in an urban area of Udaipur, Rajasthan. Indian Journal Community Medicine, 29(1), pp. $35-40$

Rajabi, Gh., Bohrani M. 2001. [Factor analysis of death anxiety question (Persian)]. Journal of Psychology, 20(2), pp. 322-344.

Salehi, F., Mohsenzade, F., \& Arefi, M. 2016. [Prevalence of death anxiety in patients with breast cancer in Kermanshah (Persian)] 2015. Iranian Journal of Breast Disease, 8(4), pp. 34-40.

Sherman, D. W., R. Norman. 2010. Comparison of death anxiety and quality of life of patients with advanced cancer or AIDS and their family caregivers. Journal of the Association of Nurses in AIDS Care, 21(2), pp. 99-112.

Schoenberg, M. H., Halle, M. 2009. Physical Activity in the Prevention and Treatment of Colorectal Carcinoma. Deutsches Arzteblatt International, 106(44), pp. 722-727. doi: 10.3238/arztebl.2009.0722

Shoja, M., Rimaz, S. H., Asadi Lari, M., Bagheri Yazdi, A., \& Govhari, M. R. 2013. [Mental health of older people and social capital (Persian)]. Journal of the Iranian Institute for Health Sciences Research, 12(4), pp. 345-353.

Statistic Center of Iran. 2012. [The results of the General Census of Population and Housing of the country (Persian)]. Tehran: Statistic Center of Iran.

Tan, S. M., Beck, K. R., Li, H., Lim, E. C. L., \& Krishna, L. K. R. 2014 Depression and anxiety in cancer patients in a Tertiary General Hospital in Singapore. Asian Journal of Psychiatry, 8, pp. 33-37. doi: 10.1016/j.ajp.2013.10.002

Templer, D. I. 1970. The construction and validation of a death anxiety scale. The Journal of General Psychology, 82(2), pp. 165-177. doi 10.1080/00221309.1970.9920634.

Vilhauer, R. P. 2008. A qualitative study of the experiences of women with metastatic breast cancer. Palliative \& Supportive Care, 6(3). doi 10.1017/s1478951508000382.pp. 249-58

Woo, E., Han, C., Jo, S. A., Park, M. K., Kim, S., Kim, E., et al. 2007. Morbidity and related factors among elderly people in South Korea: Results from the Ansan Geriatric (AGE) cohort study. BMC Public Health, 7:10, pp. 1-9. doi: 10.1186/1471-2458-7-10

World Health Organization. Ageing and life course. 2014. Geneva: World Health Organization.

Henrie J., Patrick J. H. 2014. Religiousness, religious doubt, and death anxiety. Journal of Aging and Human Development. Journal of Concel Psychother, 78(3), pp. 203-227. 